\title{
Long-term follow-up of bioprosthetic aortic valve replacement in patients aged $\leq 60$ years
}

\author{
Amedeo Anselmi, MD, PhD, Erwan Flecher, MD, PhD, Celine Chabanne, MD, \\ Vito Giovanni Ruggieri, MD, PhD, Thierry Langanay, MD, Hervé Corbineau, MD, Alain Leguerrier, MD, \\ and Jean-Philippe Verhoye, MD, PhD
}

\section{ABSTRACT}

Objective: To address the long-term durability of bioprostheses used for aortic valve replacement (AVR) in adult patients aged $\leq 60$ years at the time of surgery.

Methods: Through a retrospective review of a prospectively collected database, we identified 416 bioprosthetic AVRs performed between 1977 and 2013. A prospective follow-up of valve-related and non-valve-related events was performed.

Results: Follow-up was $98.5 \%$ complete (2423.1 patient-years; average, $6 \pm 5.5$ years). At 15 years, overall survival was $62.1 \pm 4.4 \%$; freedom from valve-related death was $97.1 \pm 1.6 \%$. There were 68 SVD events (11.9 \pm 28.8 years after surgery). Freedom from SVD at 15 years was 48.7 $\pm 5.5 \%$ for Kaplan-Meier analysis and $61.4 \pm 4.3 \%$ for competing-risks analysis. After stratification into age subgroups $(<40$ years, $\geq 40$ and $<50$ years, and $\geq 50$ and $\leq 60$ years), we observed no significant difference in freedom from SVD $(P=.50)$. The average delay to SVD was not statistically different among subgroups $(P=.30)$. There were 57 reoperations for SVD (11.8 \pm 5.2 years after implantation). The 15 year freedom from reoperation for SVD was $55.4 \pm 5.6 \%$ by Kaplan-Meier analysis and $67.1 \pm 4.2 \%$ by competing-risks analysis. After stratification by age, freedom from reoperation for SVD was comparable $(P=.13)$. Freedom from any valve-related complication or death was $42 \pm 5 \%$ by Kaplan-Meier analysis and $54.4 \pm 4.1 \%$ by competing-risks analysis.

Conclusions: The lifetime risk of SVD is considerable in patients aged $\leq 60$ years at the time of bioprosthesis implantation. Nonetheless, durability remains consistent during the first decade; additional data are required for the second decade. Patients' information is pivotal for valve choice (competing-risks method). ( $\mathrm{J}$ Thorac Cardiovasc Surg 2017;154:1534-41)

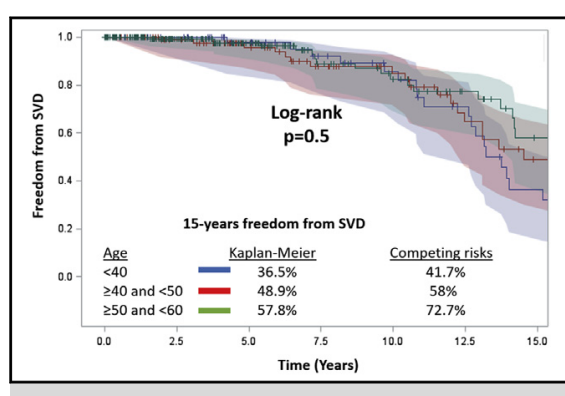

Long-term freedom from bioprosthetic SVD in patients aged $\leq 60$ (by age subgroups). Error estimates ( $95 \%$ confidence interval) are given as shaded areas. Group 1, blue line; group 2, red line; group 3, green line.

\section{Central Message}

The risk of bioprosthetic structural valve deterioration (SVD) is consistent in patients aged $\leq 60$ years, yet there is no accelerated SVD in the first decade and rare thromboembolic/hemorrhagic complications.

\section{Perspective}

Given consistent durability, use of bioprostheses for aortic valve replacement in younger patients is expected to further expand. The present data may contribute to the reflection over staged protocols involving endovalvular therapy, and at the same time constitute a reference for comparison for durability of transcatheter heart valves.

See Editorial Commentary page 1542.
Recent years have seen a progressive shift toward the more liberal use of bioprostheses for aortic valve replacement (AVR) in younger patients. ${ }^{1}$ Accordingly, recent European

From the Division of Thoracic and Cardiovascular Surgery, Pontchaillou University Hospital, Rennes, France.

Received for publication June 12, 2016; revisions received April 29, 2017; accepted for publication May 30, 2017; available ahead of print July 6, 2017.

Address for reprints: Amedeo Anselmi, MD, PhD, Division of Thoracic and Cardiovascular Surgery, Pontchaillou University Hospital, 2 rue Henri Le Guilloux, Rennes 35 033, France (E-mail: amedeo.anselmi@alice.it).

0022-5223/\$36.00

Copyright (c) 2017 by The American Association for Thoracic Surgery

http://dx.doi.org/10.1016/j.jtcvs.2017.05.103 and North American guidelines have suggested lower age limits for the use of bioprostheses in AVR, and have emphasized the importance of considering patients' preference in valve choice. ${ }^{2,3}$ This trend is being driven by evidence of improved durability of the latest generation of stented

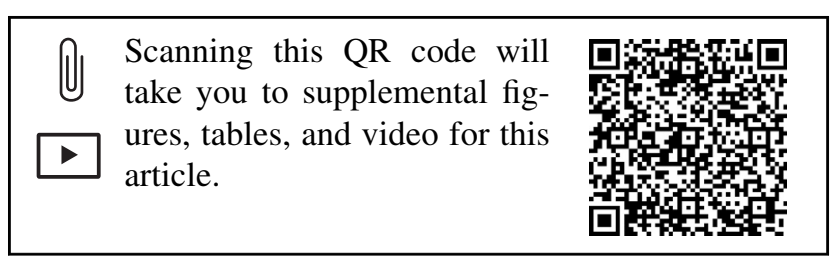




\section{Abbreviations and Acronyms \\ AVR = aortic valve replacement \\ IE $=$ infective endocarditis \\ iEOA $=$ indexed effective orifice area \\ NSVD $=$ nonstructural valve dysfunction \\ SVD = structural valve deterioration}

valve devices (amelioration in anticalcification treatments), and also by the availability and reproducibility of the valve-in-valve transcatheter technique for the treatment of degenerated bioprostheses. ${ }^{4,5}$ Notwithstanding, this context needs to clarify whether the excellent durability noted for latest-generation bioprostheses in older age groups ${ }^{6,7}$ can be reliably transferred to younger surgical candidates. Such information is of pivotal importance in the discussion of potential treatment algorithms involving elective bioprosthetic AVR in younger candidates and the foreseen later use of the transcatheter valve-in-valve technique.

The purpose of the present investigation was to provide data about the long-term durability of bioprostheses used for AVR in patients aged $\leq 60$ years at the time of surgery. Such information might be relevant to the discussion of evolving protocols for treating aortic valve disease, and for preoperative consultation with patients with respect to valve choice.

\section{PATIENTS AND METHODS}

\section{Patient Selection and Data Management}

We conducted a retrospective review of our institutional database to identify all patients aged $\leq 60$ years who underwent AVR with a bioprosthesis (any model) between January 1977 and December 2013. The database contains preoperative variables, intraoperative characteristics, and early postoperative results, including control transthoracic echocardiography. Globally, the characteristics of 36,799 cardiac surgical operations are available. Data on all patients undergoing cardiac surgery at our center were collected prospectively at the time of hospital discharge. Research nurses, under the supervision of the surgical team, perform periodic verifications of consecutiveness of inclusions and completeness of the dataset. The performance of any associated valvular or cardiac procedure other than AVR and history of previous cardiac surgery did not constitute exclusion criteria. Long-term follow-up was conducted by research nurses; the referring cardiologists were provided with a questionnaire enquiring about the patient's vital status, the occurrence and description of adverse events, cause of death, and the time of the adverse event or death. In cases where data could not be retrieved from the referring cardiologists, general practitioners and the patients themselves (or family members) were contacted. Local authorities were questioned about the patient's vital status in case of failure of the above modes. The study outline is reported in Figure 1. Follow-up was completed in $98.5 \%$ of patients, and we had 2423.1 patient-years available for analysis. The average duration of follow-up was $6 \pm 5.5$ years, and with the longest duration 28.8 years.

Valve-related and non-valve-related adverse events were defined according to the recommendations of Akins and colleagues, ${ }^{8}$ and included structural valve deterioration (SVD), nonstructural valve dysfunction (NSVD), and prosthetic infective endocarditis (IE). In particular, SVD was distinguished from reoperation for SVD, and the corresponding freedom rates were presented separately. In patients with multiple valve devices,

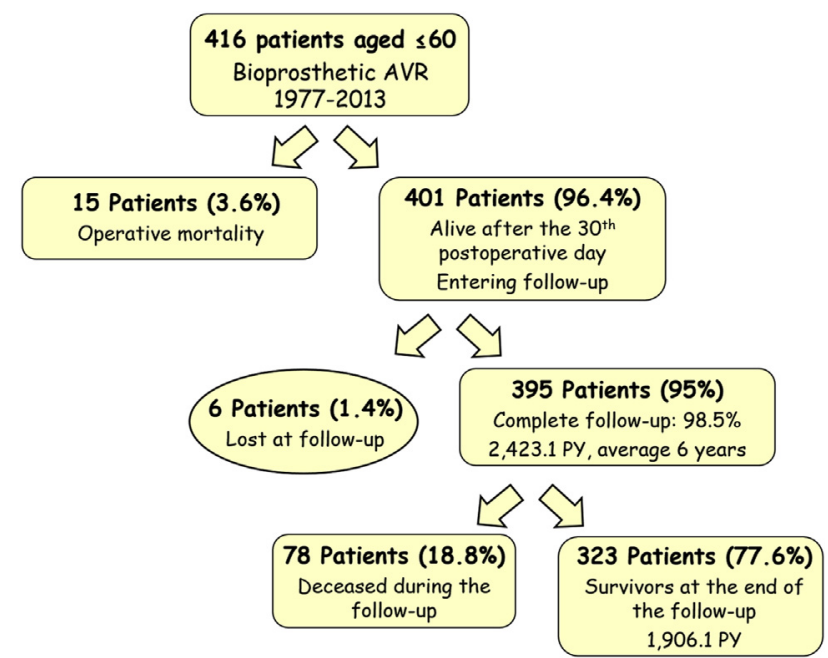

FIGURE 1. CONSORT diagram of the study. $A V R$, Aortic valve replacement; $P Y$, patient-years.

medical records were reviewed to adjudicate the events to either the index valve (ie, the bioprosthesis in the aortic position) or to another device, eventually leading to exclusion of the selected event from the present analysis. Cerebral or noncerebral systemic thromboembolic events were systematically attributed to the aortic prosthesis unless another origin could be formally demonstrated (eg, thrombosis of a coexisting prosthesis in the mitral position with evidence of normal aortic valve prosthesis). Similarly, reinterventions were defined as valve-related when the indication to reoperate derived from any dysfunction of the bioprosthesis in the aortic position.

Valve-related mortality was defined as any death occurring after reintervention on the index valve or occurring owing to any adverse event attributed to the index valve. In cases of insufficient information about the causes of death, the mortality event was considered valve-related, according to the recommendations. ${ }^{8}$ For patients receiving a reoperative bioprosthetic AVR, the day of reoperation was considered the end of the follow-up for the first bioprosthesis and the beginning of the follow-up of the second bioprosthesis. Patient-prosthesis mismatch was defined based on discharge echocardiography as either severe (indexed effective orifice area [iEOA] $\left.\leq 0.65 \mathrm{~cm}^{2} / \mathrm{m}^{2}\right)$, moderate $\left(0.65 \mathrm{~cm}^{2} / \mathrm{m}^{2}<\right.$ iEOA $\left.\leq 0.85 \mathrm{~cm}^{2} / \mathrm{m}^{2}\right)$, or absent (iEOA $>0.85 \mathrm{~cm}^{2} / \mathrm{m}^{2}$ ).

All patient data were managed anonymously. The present study did not involve any additional diagnostic or therapeutic procedure than standard clinical practice; therefore, the requirement for patient informed consent to enter this investigation was waived. Our database is registered within the CNIL (Commission Nationale de l'Informatique et des Libertées [National Committee for Informatics and Freedom]) archive under number 1207754, according to French law.

A total of 416 bioprosthetic AVR procedures in 395 patients met our inclusion criteria for the study. Table 1 reports baseline characteristics of our entire study cohort. Of note, the cohort is characterized by low rates of comorbidities and equilibrated distribution of stenosis and regurgitation as the modality of aortic valve failure. Table E1 summarizes the intraoperative details and the types of bioprostheses used. Urgent or emergent priority was assigned to $14 \%$ of the cases. There was a considerable rate of associated procedures $(34.9 \%$ overall), the majority of which were involved concomitant thoracic aortic surgery (including 26 cases of supracoronary ascending aortic replacement [17.8\%], 13 Bentall procedures $[8.9 \%]$, and 10 other thoracic aortic operations [6.8\%]) and valve procedures other than AVR (34 cases of concomitant mitral valve replacement $(8.2 \%), 4$ cases of concomitant tricuspid or pulmonary valve replacement $(1 \%), 8$ cases of concomitant mitral repair 
TABLE 1. Baseline characteristics of the overall study population

\begin{tabular}{|c|c|}
\hline Characteristic & Value \\
\hline Age, $y$, mean \pm SD & $48.4 \pm 10.6$ \\
\hline \multicolumn{2}{|l|}{ Age subgroup, $\mathrm{n}(\%)$} \\
\hline$<40 \mathrm{y}$ & 77 (18.5) \\
\hline$\geq 40$ and $<50 y$ & $107(25.7)$ \\
\hline$\geq 50$ and $\leq 60 \mathrm{y}$ & $232(55.8)$ \\
\hline Male sex, n (\%) & $347(83.4)$ \\
\hline NYHA III or IV, n (\%) & $192(46.6)$ \\
\hline Diabetes, n (\%) & $30(7.2)$ \\
\hline Peripheral arterial disease, $\mathrm{n}(\%)$ & $25(6)$ \\
\hline Renal insufficiency, n (\%) & $16(3.9)$ \\
\hline COPD, n (\%) & $32(7.7)$ \\
\hline $\mathrm{LVEF}, \%$, mean $\pm \mathrm{SD}$ & $58.4 \pm 13$ \\
\hline \multicolumn{2}{|c|}{ Modality of aortic valve dysfunction, $\mathrm{n}(\%)$} \\
\hline Prevalent stenosis & $181(43.5)$ \\
\hline Prevalent regurgitation & $165(39.7)$ \\
\hline Combined & $70(16.8)$ \\
\hline $\begin{array}{l}\text { Bicuspid or quadricuspid aortic } \\
\quad \text { valve, } n(\%)\end{array}$ & $149(35.8)$ \\
\hline Marfan syndrome, n (\%) & $6(1.4)$ \\
\hline Infective endocarditis, n (\%) & $77(18.5)$ \\
\hline Previous cardiac surgery, n (\%) & $17(7.1)$ \\
\hline $\begin{array}{l}\text { Third-degree atrioventricular } \\
\text { block, n }(\%)\end{array}$ & $13(3.1)$ \\
\hline $\begin{array}{l}\text { Second- or third-degree } \\
\text { atrioventricular block, n (\%) }\end{array}$ & $4(0.9)$ \\
\hline Permanent pacemaker, n (\%) & $6(1.4)$ \\
\hline
\end{tabular}

$S D$, Standard deviation; NYHA, New York Heart Association; COPD, chronic obstructive pulmonary disease; $L V E F$, left ventricular ejection fraction.

[1.9\%], and 8 other valve procedures [1.9\%]). Video 1 depicts 1 case of AVR with a third-generation bioprosthesis with associated coronary bypass.

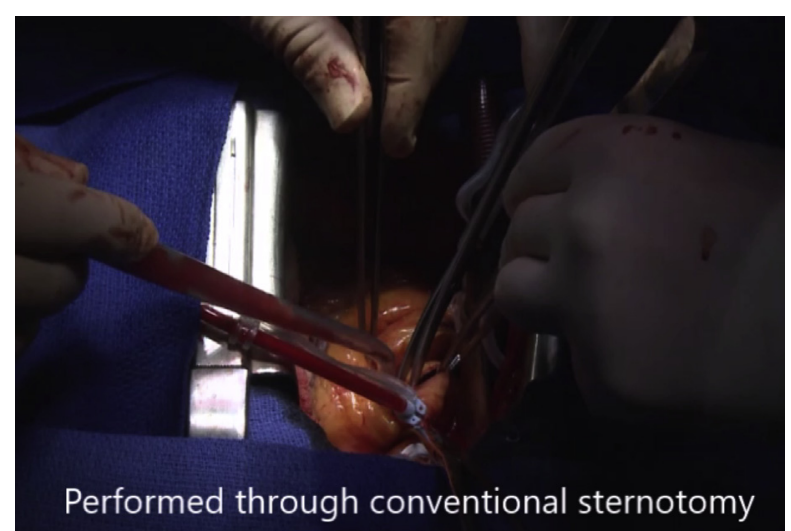

VIDEO 1. Aortic valve replacement using a third-generation pericardial bioprosthesis in a study patient. Video available at: http://www. jtcvsonline.org/article/S0022-5223(17)31187-X/addons.

\section{Endpoints}

Study endpoints were (1) long-term survival free from SVD, from reoperation for SVD, and from any valve-related adverse event in patients aged $\leq 60$ years undergoing AVR using a bioprosthesis; (2) stratified survival, freedom from bioprosthetic SVD and reoperation for SVD according to age subgroup at the time of surgery ( $<40,40-50$, or 51-60 years); and (3) delay to occurrence of bioprosthetic SVD in patients aged $\leq 60$ years at the time of surgery and comparative evaluation among subgroups according to age.

\section{Statistical Analysis}

Continuous data are reported as mean \pm standard deviation; categorical data, as number and percentage. The 2-tailed Student's $t$ test was used for intergroup comparisons after verification of the normality of data distribution through the Kolmogorov-Smirnoff test. The Kruskal-Wallis test was used for multiple-group comparisons. In time-to-event analysis, both the Kaplan-Meier (actuarial) and the competing-risks (actual) methods were used, as described previously. ${ }^{7,10-12}$ The log-rank statistic was used to compare stratified actuarial curves; all deaths since surgery were included in the calculation of Kaplan-Meier estimates. To identify predictors of mortality and SVD (response variables), we built dedicated Cox proportional hazards regression models. All available preoperative and intraoperative data were entered as potential explanatory variables. Variables with $P \leq .20$ on univariate analysis were entered into the final multivariate model (stepwise methodology). The assumptions of Cox regression were checked and met, and the models were tested. We built another Cox proportional hazards regression model to test the association between mortality/survival and SVD (assessment of independency of censoring). Analyses were done using SAS version 9.33 (SAS Institute, Cary, NC) and the $\alpha$ level was set at 0.05 .

\section{RESULTS \\ Early Results}

Operative mortality was $3.6 \%$. Associated procedures were performed in $34.9 \%$ of the cases, including valvular other than aortic in $13 \%$, thoracic aorta in $12.3 \%$, coronary bypass in $5.8 \%$, and other in $3.8 \%$. After stratification of the population into 3 groups according to age at surgery (group $1,<40$ years; group $2, \geq 40$ and $<50$ years; group $3, \geq 50$ and $\leq 60$ years), we observed a significantly higher rate of IE as the etiology of valve disease in the younger subgroups $(28.6 \%$ in group $1,21.5 \%$ in group 2 , and $13.8 \%$ in group $3 ; P=.009$ ). Conversely, degenerative calcified valve disease was more frequent in older strata $(5.2 \%$ in group $1,15 \%$ in group 2 , and $28.9 \%$ in group 3; $P<.001$ ), whereas there was no significant difference in the distribution of rheumatic heart disease across the groups $(15.6 \%$ in group $1,12.1 \%$ in group 2 , and $7.8 \%$ in group $3 ; P=.15)$. Other intergroup comparisons are reported in Table E2.

Average cardiopulmonary bypass time was significantly longer among the patients undergoing concomitant procedures compared with those undergoing isolated AVR $(132.3 \pm 66.2$ minutes vs $67.5 \pm 29$ minutes; $P<.001)$. A significant difference between the 2 groups also was seen in average aortic cross-clamping time (103.2 \pm 51.4 minutes vs $52.4 \pm 22.8$ minutes; $P<.001$ ). Operative 
mortality was $3.6 \%$ in the overall population $(n=15)$. In addition, operative mortality was statistically higher in patients undergoing concomitant procedures associated with AVR (6.9\% vs $1.8 \%$ for isolated AVR; $P=.0085)$. Causes of operative mortality ware valve-related in 2 cases $(1.4 \% ; 1$ stroke and 1 early valve-related reoperation), cardiac non-valve-related in 8 cases $(5.5 \%)$, and extracardiac in 5 cases $(3.4 \%)$. Of the 19 early reoperations $(4.6 \%), 18$ were valve-related.

\section{Long-Term Follow-up}

Overall 15-year survival was $62.1 \pm 4.4$ years (78 death events at follow-up). The Kaplan-Meier overall survival curve is shown in Figure 2, A. Causes of mortality at follow-up were valve-related in 7 cases $(1.7 \%)$, cardiac non-valve-related in 8 cases $(1.9 \%)$, extracardiac in 32 cases $(7.7 \%)$, and unknown in 31 cases $(7.4 \%)$. The 15 year freedom from valve-related death was $97.1 \pm 1.6 \%$.

A total of 68 SVD events were recorded during the follow-up, occurring at an average of $11.9 \pm 28.8$ years after surgery. In the overall population, the freedom from
SVD at 15 years was $48.7 \pm 5.5 \%$ according to the actuarial method (Figure 2, B) and $61.4 \pm 4.3 \%$ according to the competing-risks method. In the stratified analysis according to age at the time of AVR, we observed significantly worse long-term survival in group 3 compared with groups 1 and 2 $(48 \pm 6.6 \%$ vs $86.4 \pm 4.8 \%$ vs $68.8 \pm 8.1 \% ; P<.001, \log$ rank test) (Figure $3, A$ ). Nonetheless, the late freedom from SVD was not statistically different across the 3 groups $(P=.50, \log$-rank lest; Figure $3, B)$. Table 2 reports the freedom from SVD at various follow-up time points stratified according to age group. Importantly, the average interval between AVR and the occurrence of SVD was not statistically different across the age subgroups $(P=.30$; Table 3), implying the absence of accelerated SVD in younger individuals.

Reoperation for SVD was performed in 57 cases $(83.8 \%$ of the SVD events), on average $11.8 \pm 5.2$ years after the index AVR. The overall 15-year freedom from reoperation for SVD was $55.4 \pm 5.6 \%$ by the actuarial method and $67.1 \% \pm 4.2 \%$ by the competing-risks method (Figure 2,C). Stratification by age did not yield significant
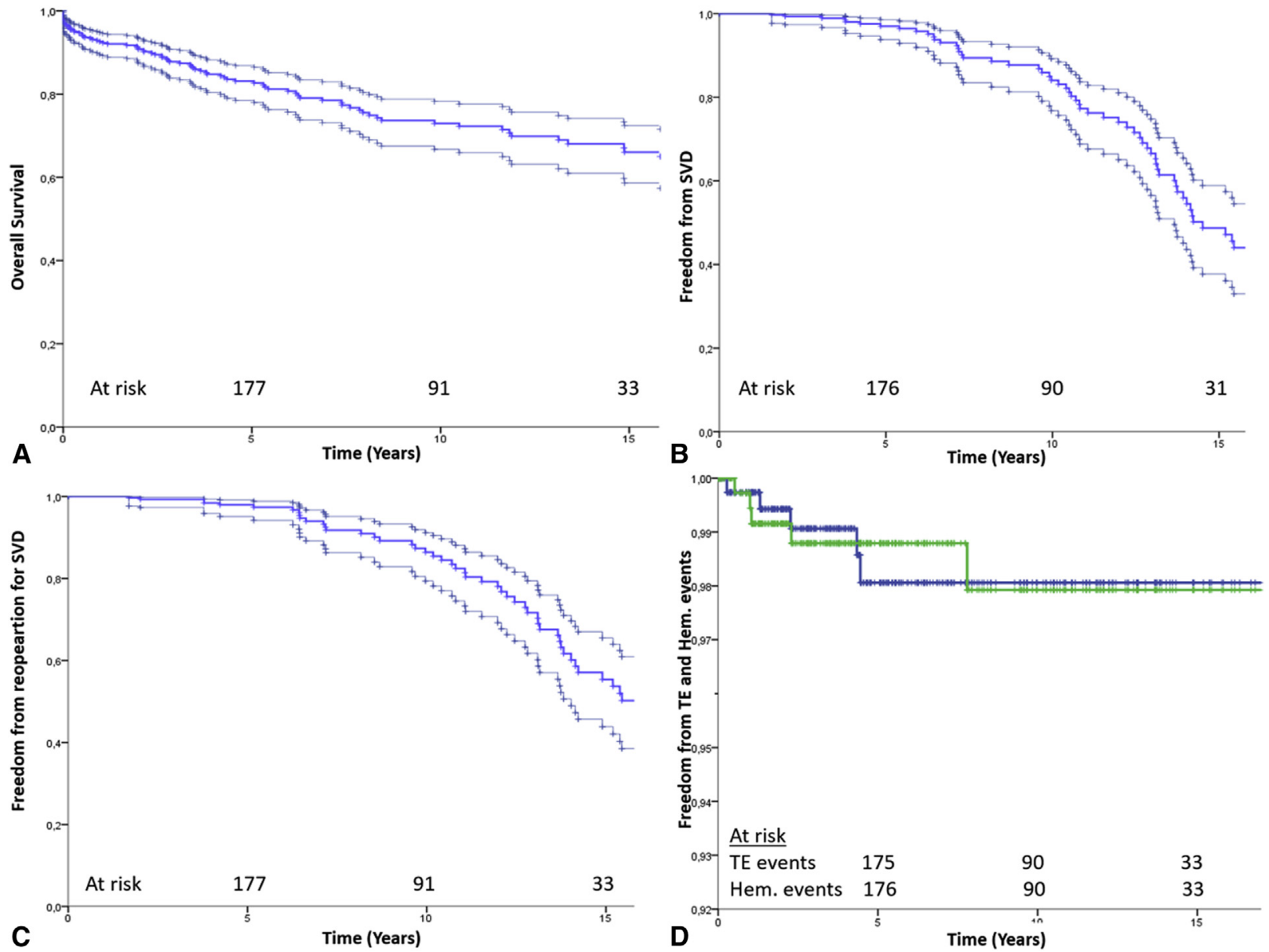

C

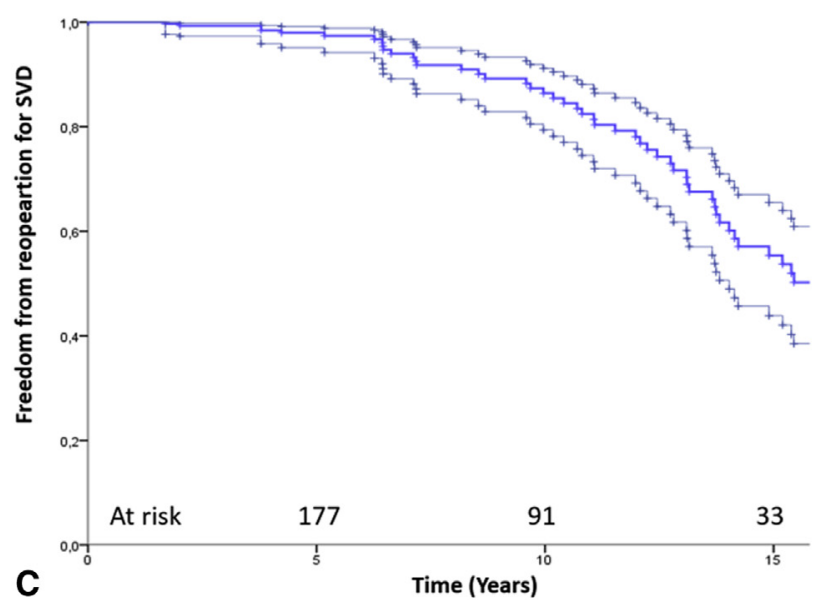

FIGURE 2. Kaplan-Meier survival curves for the entire study population. Number of patients at risk are reported above each timepoint. Peripheral curves indicate $95 \%$ confidence intervals. A, Overall survival. B, Freedom from SVD. C, Freedom from reoperation for SVD. D, Freedom from hemorrhagic (green line) and thromboembolic complications (blue line). SVD, Structural valve deterioration; TE, thromboembolic; Hem., hemorrhagic. 

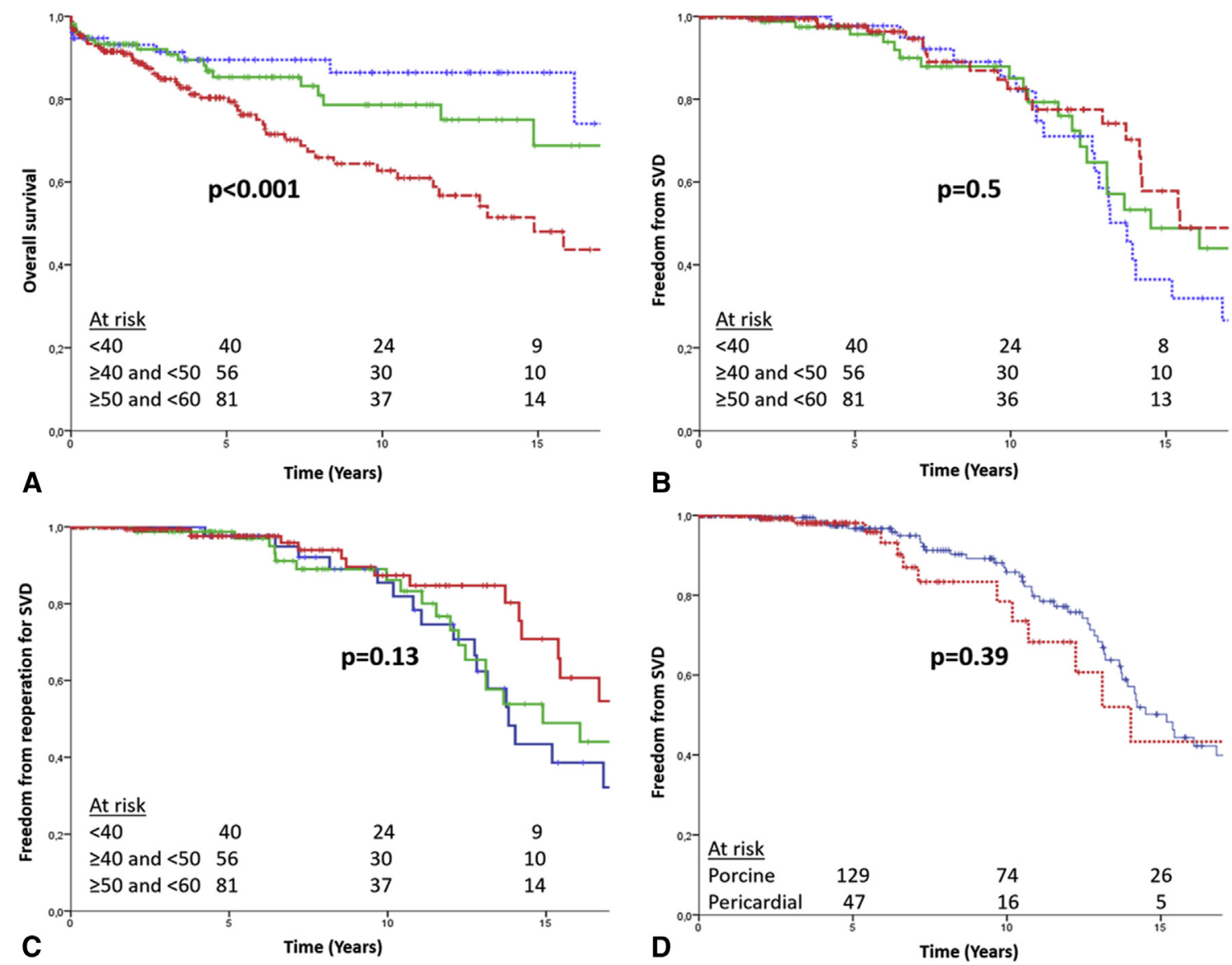

FIGURE 3. Kaplan-Meier survival curves stratified according to age groups at surgery. Number of patients at risk are reported above each time point, and log-rank $P$-values are displayed. Group 1: blue line; Group 2: green line; Group 3: red line. A, Overall survival. B, Freedom from SVD. C, Freedom from reoperation for SVD. D, Freedom from SVD according to valve type in the entire population (blue line: porcine; red line: pericardial). Table E3 reports the confidence limits for the Kaplan-Meier curves shown here. SVD, Structural valve deterioration.

intergroup differences in terms of late freedom from reoperation for $\operatorname{SVD}(P=.13$; Figure $3, C)$. Details of freedom from reoperation from SVD by subgroup are reported in Table 4. Eleven patients with SVD did not require reoperation at the end of follow-up owing to stable and moderate valve dysfunction, with good clinical tolerance. There were no cases of transcatheter valve-in-valve in the present series.

Globally, there were 14 NSVD events (15-year freedom: $92.9 \pm 2.8 \%$ by the actuarial method and $94.2 \pm 2.1 \%$ by the competing-risks method), 9 of which required reoperation. We observed 9 IE events involving the index bioprosthesis (15-year freedom, $96.8 \pm 1.2 \%$ for actuarial, $97.1 \pm 1 \%$ for competing-risks), 7 of which required reoperation. We noted particularly high rates of freedom at 15 years for both thromboembolic events (actuarial, $98.1 \pm 0.9 \%$; competing risks, $98.2 \pm 0.8 \%$ ) and hemorrhagic events (actuarial, $97.9 \pm 1 \%$; competing risks, $98.1 \pm 0.9 \%$ ) (Figure $2, D$ ). A total of 75 valve-related reinterventions were performed during follow-up (56 due to SVD, 9 to NSVD, 7 to IE, and 3 to a thromboembolic event). Long-term freedom from any valve-related reintervention was $49.9 \pm 5.3 \%$ by the actuarial method and $62.1 \% \pm 4.1$ by the competing-risks method. At 15 years, the freedom from any valve-related complication or death was $42 \pm 5 \%$ for actuarial and $54.4 \pm 4.1 \%$ for competing-risks; these events involved SVD in the majority of cases. Actuarial freedom from any valve-related complication at follow-up was not statistically different among the 3 subgroups stratified by age at surgery $(P=.49, \log$-rank test).

\section{Substudy: Stratification According to Valve Type}

In a further analysis, we sought to compare the differential outcomes in terms of SVD between patients receiving a porcine bioprosthesis and those receiving a pericardial bioprosthesis (any model). The relative use of porcine versus pericardial bioprostheses has evolved over time, changing from $53.3 \%$ porcine versus $46.7 \%$ pericardial in 1997 to 1980 , to $74.1 \%$ versus $25.9 \%$ in 1981 to 1990 , and to $95.9 \%$ versus $4.1 \%$ in 1991 to 2000 . However, more recent years have brought a major reduction in the use of porcine 
TABLE 2. Freedom from SVD stratified according to age subgroup (survivors to surgery)

\begin{tabular}{|c|c|c|c|c|c|}
\hline Age group, $y$ & Total patients, $\mathbf{n}$ & SVD events, n & 5-y follow-up, $\%$ & 10-y follow-up, $\%$ & 15-y follow-up, $\%$ \\
\hline$<40$ & 73 & 22 & $97.7(97.8)$ & $85.5(86.4)$ & $36.5(41.7)$ \\
\hline$\geq 40$ and $<50$ & 104 & 25 & $95.7(96)$ & 85 (86.7) & $48.9(58)$ \\
\hline$\geq 50$ and $\leq 60$ & 224 & 21 & $97.6(97.9)$ & $82.5(87.1)$ & $57.8(72.7)$ \\
\hline Total & 401 & 68 & $97(97.3)$ & $84.1(87.1)$ & $48.7(61.4)$ \\
\hline
\end{tabular}

Actuarial rates are reported; rates calculated with the competing-risks method are in parentheses. $S V D$, Structural valve deterioration.

bioprostheses, with rates of $53.5 \%$ porcine versus $46.4 \%$ pericardial in 2001 to 2010 and $21.9 \%$ versus $78.1 \%$ in 2011 to 2013. In the porcine bioprostheses subgroup, 15year freedom from SVD was $50.2 \pm 6 \%$ by the actuarial method and $63.5 \pm 4.7 \%$ by the competing-risks method. In the pericardial bioprostheses subgroup, long-term freedom from SVD was $43.3 \pm 13 \%$ for actuarial and $52.4 \pm 11.1 \%$ for competing-risks. There was no statistically significant difference between the groups $(P=.39$, log-rank test; Figure $3, D$ ). Similarly, no statistically significant difference in the average delay to occurrence of SVD was noted $(12.3 \pm 5.3$ years for porcine bioprostheses vs $10.5 \pm 6.2$ years for pericardial bioprostheses; $P=.27$ ). Table E4 reports the freedom from SVD stratified according to generation of bioprostheses. Figure E2 shows the corresponding Kaplan-Meier curves. No significant intergroup differences were observed with respect to freedom from SVD.

\section{DISCUSSION}

The expanding use of bioprostheses for AVR during recent years (Figure E1) has been supported by evidence of optimal durability ${ }^{7,12-15}$ and by a progressive decrease in the risk of reoperative AVR. ${ }^{16,17}$ Recent recommendations have underlined the preference of informed patients as a criterion in the choice among bioprostheses and mechanical valves. ${ }^{2,3}$ Thus, a rigorous evaluation of the fate of bioprostheses implanted for AVR in younger patients is important.

In the present single-center study, we followed up 416 bioprostheses implanted in the aortic position in patients aged $\leq 60$ years at the time of surgery. During the early years of our experience, the main reasons for using a

TABLE 3. Average delay to occurrence of SVD stratified according to age group

\begin{tabular}{lccc}
\hline & & \multicolumn{2}{c}{ Delay } \\
\cline { 3 - 4 } Age group, $\mathbf{y}$ & SVD events, $\mathbf{n}$ & Mean $\pm \mathbf{S D}, \mathbf{y}$ & Median, $\mathbf{y}$ \\
\hline$<40$ & 22 & $13.2 \pm 5.7$ & 12.8 \\
$\geq 40$ and $<50$ & 25 & $12.3 \pm 5.9$ & 12.2 \\
$\geq 50$ and $\leq 60$ & 21 & $10.1 \pm 4.6$ & 9.9 \\
Total & 68 & $11.9 \pm 5.5$ & 12.1 \\
\hline
\end{tabular}

SVD, Structural valve deterioration; $S D$, standard deviation. bioprosthesis were a contraindication to anticoagulant treatment, patient preference, and pregnancy in young women; patient preference has become an increasingly important factor in more recent years (data not shown). Moreover, as an institutional policy we have often preferred bioprostheses for IE with severe perivalvular extension. The $98.5 \%$ rate of complete follow-up and available 2423.1 patient-years make this one of the largest and most complete studies of this topic reported to date. In our global population, the freedom from SVD at 15 years was $48.7 \%$ by the actuarial method and $61.4 \%$ by the competing-risks method. One previous series with a similar population reported a $31.6 \%$ actuarial freedom from SVD at 15 years, ${ }^{18}$ whereas another series reported a $70.8 \%$ actuarial freedom from reoperation for SVD at 15 years (38.1\% at 20 years), ${ }^{19}$ with 17.6 years of expected valve durability. In our series, the freedom from reoperation related to SVD was $55.4 \%$ by the actuarial method and $67.1 \%$ by the competingrisks method at the same time point. Using the competing-risks method, the 20-year risk of reoperation due to SVD is $41.6 \%$ in our series, which compares positively with our $32.9 \%$ actuarial risk at 15 years. ${ }^{12}$ Other studies have reported a $57 \%$ actuarial 15 -year freedom from SVD (although limited by a small sample size) ${ }^{20}$ and a $46 \%$ actuarial freedom from reoperation due to SVD at 20 years $^{6}$; some others did not attain long-term follow-up. ${ }^{21}$ These apparent discrepancies might be related to the use of various models of bioprostheses in our series. ${ }^{18}$ In addition, our population included a significantly higher proportion of patients aged $<40$ years at surgery $(20.7 \%$ vs $16 \%$ ), with the potential for a greater frequency of SVD cases.

Overall, the data suggest consistent durability of modern bioprostheses in younger individuals. The rates of freedom from SVD and related reinterventions as calculated using the competing-risks method should be shared with patients during preoperative consultation. The actuarial (KaplanMeier) methodology would provide excessively pessimistic estimations for this purpose. SVD and the related reinterventions are often nonlethal events and are subject to censoring by death due to other causes. ${ }^{8,10,11}$ In the present study, we found an association between survival and the risk of SVD $(P<.001$, Cox hazard regression; risk ratio, 5.66; 95\% confidence interval, 2.05-15.61); thus, censoring is not independent, and the SVD-related 
TABLE 4. Freedom from reoperation for SVD stratified according to age group (survivors to surgery)

\begin{tabular}{lccccc}
\hline & & Reoperation for SVD events, & & & \\
Age group, $\mathbf{y}$ & Total patients, $\mathbf{n}$ & $\mathbf{n}$ & $\mathbf{5 - y}$ follow-up, \% & $\mathbf{1 0 - y}$ follow-up, \% & $\mathbf{1 5 - y}$ follow-up, \% \\
\hline$<40$ & 73 & 19 & $97.7(97.8)$ & $85.5(86.4)$ & $43.4(48)$ \\
$\geq 40$ and $<50$ & 104 & 23 & $98.7(98.8)$ & $86.1(87.9)$ & $48.9(59.2)$ \\
$\geq 50$ and $\leq 60$ & 224 & 15 & $97.6(97.9)$ & $87.3(90.8)$ & $70.8(81.7)$ \\
Total & 401 & 57 & $98(98.1)$ & $86.4(89)$ & $55.4(67.1)$ \\
\hline
\end{tabular}

Actuarial rates are reported; rates calculated with the competing risks method are in parentheses. $S V D$, Structural valve deterioration.

outcomes can be better addressed through the competingrisks methodology. The accumulation of lethal events not related to SVD is likely to be less important in our present series than in series composed of elderly subjects. ${ }^{7}$ Group 1 included fewer patients attaining the 15-year time point in our stratified analysis; nonetheless, group 1 also had the highest rate of patients achieving the 15-year follow-up among the 3 subgroups.

Although the frequency of SVD is greater in the younger age subgroups, we failed to demonstrate accelerated development of SVD (Table 2), instead finding a rate similar to that in older populations receiving second-generation porcine bioprostheses. ${ }^{15}$ This type of analysis is described here for the first time in patients aged $<60$ years at the time of surgery. Even longer delays to the occurrence of SVD (17.6 years) have been reported recently. ${ }^{19}$ Although series with very young patients $(<30$ years) are limited, the data suggest that similar durability of bioprostheses for AVR can be expected in 40-year-old and 60-year-old recipients. Multivariate analysis found no association between age and the development of SVD (Tables E5 and E6).

Accumulating evidence suggests similar long-term survival in recipients of bioprostheses and recipients of mechanical valves. ${ }^{22-24}$ Survival free from any valve-related adverse events may be better if a mechanical prosthesis is used in patients age $<65 .{ }^{25}$ Nonetheless, we need to consider not only the crude rate of adverse events, but also their nature and impact on patients' quality of life. ${ }^{26}$ Intracranial bleeding is more likely to result in disability and recurrent hospitalizations. Bioprostheses are associated with a very low rate of thromboembolic and hemorrhagic complications (Figure 2,D), and younger patients with an active lifestyle will typically benefit from the absence of anticoagulant treatment. ${ }^{27}$

The need to manage an increasing number of SVD cases can be anticipated in the future. Although reoperative isolated AVR is considered a lower-risk procedure than other cardiac reinterventions, younger patients typically undergo primary AVR in the context of aortic surgery or severe endocarditis at a higher rate than elderly patients. These factors are likely to increase the risk of iterative surgery for bioprosthetic SVD, and should be considered when weighing valve options. The possibility of transcatheter valve-in-valve as a bailout procedure, along with its technical limitations (eg, elevated transvalvular gradients in smaller diameters, periprosthetic regurgitation, coronary obstruction, need for a permanent pacemaker, device migration, unknown durability), need to be taken into account. $^{28,29}$ Strategies including staged surgical and endovascular approaches for an intended "bioprosthetic" management of younger candidates need to be evidencebased. Recent data have raised concerns about an increased rate of SVD between 5 and 7 years after implantation of transcatheter valves. ${ }^{30}$ Here we were unable to establish a link between the etiology of valve disease and lifetime risk of SVD. In a previous investigation, ${ }^{7}$ we identified patient age as the sole independent predictor of SVD. Although its impact on the durability of bioprostheses is debatable, renal insufficiency should be considered caseby-case when choosing a valve, especially if the lifetime risk of dialysis is important.

The present study reinforces that "historical" bioprosthetic AVR recipients aged $\leq 60$ years have a different profile than their older homologs (Table 1). Nevertheless, we can reasonably expect that the current tendency toward the use of bioprostheses at younger ages will persist. Although the lifetime risk of SVD is considerable in patients aged $\leq 60$ at the time of surgery, the durability of bioprostheses remains consistent during the first decade, with no evidence of accelerated SVD. Additional data are needed for the second decade. We found no difference in long-term freedom from SVD across age subgroups, with a very low risk of thromboembolic and hemorrhagic events in the long term. The use of multiple valve models in our series is a limitation of this work. The small proportion of patients attaining the latest follow-up time point also needs to be considered. For the choice of valve substitute, patient preference should be considered only after the patient is provided with detailed information about the lifetime risk of SVD and other valve-related events (the competing-risks method).

\section{Conflicts of Interest Statement}

Authors have nothing to disclose with regard to commercial support.

We thank Sylvie Marie and Anne Ingels for their help with longterm follow-up and statistical analysis. 


\section{References}

1. Bridgewater B, Keogh B. Sixth National Adult Cardiac Surgical Database Report: Demonstrating Quality, 2008. Henley-on-Thames, UK: Dendrite Clinical Systems Ltd; 2009.

2. Vahanian A, Alfieri O, Andreotti F, Antunes MJ, Barón-Esquivias G, Baumgartner $\mathrm{H}$, et al. Guidelines on the management of valvular heart disease (version 2012): the Joint Task Force on the Management of Valvular Heart Disease of the European Society of Cardiology (ESC) and the European Association for Cardio-Thoracic Surgery (EACTS). Eur J Cardiothorac Surg. 2012;42:S1-44.

3. Nishimura RA, Otto CM, Bonow RO, Carabello BA, Erwin JP III, Guyton RA, et al. 2014 AHA/ACC guideline for the management of patients with valvular heart disease: a report of the American College of Cardiology/American Heart Association Task Force on Practice Guidelines. J Thorac Cardiovasc Surg. 2014;148:e1-132.

4. Bapat V, Attia R, Redwood S, Hancock J, Wilson K, Young C, et al. Use of transcatheter heart valves for a valve-in-valve implantation in patients with degenerated aortic bioprosthesis: technical considerations and results. J Thorac Cardiovasc Surg. 2012;144:1372-80.

5. Dvir D, Webb J, Brecker S, Bleiziffer S, Hildick-Smith D, Colombo A, et al. Transcatheter aortic valve replacement for degenerative bioprosthetic surgical valves: results from the global valve-in-valve registry. Circulation. 2012;126:2335-44.

6. Johnston DR, Soltesz EG, Vakil N, Rajeswaran J, Roselli EE, Sabik JF III, et al. Long-term durability of bioprosthetic aortic valves: implications from 12,569 implants. Ann Thorac Surg. 2015;99:1239-47.

7. Anselmi A, Flécher E, Ruggieri VG, Harmouche M, Langanay T, Corbineau H, et al. Long-term results of the Medtronic Mosaic porcine bioprosthesis in the aortic position. J Thorac Cardiovasc Surg. 2014;147:1884-91.

8. Akins CW, Miller DC, Turina MI, Kouchoukos NT, Blackstone EH, Grunkemeier GL, et al. Guidelines for reporting mortality and morbidity after cardiac valve interventions. J Thorac Cardiovasc Surg. 2008;135:732-8.

9. Blais C, Dumesnil JG, Baillot R, Simard S, Doyle D, Pibarot P. Impact of valve prosthesis-patient mismatch on short-term mortality after aortic valve replacement. Circulation. 2003;108:983-8.

10. Grunkemeier GL, Jin R, Eijkemans MJ, Takkenberg JJ. Actual and actuarial probabilities of competing risks: apples and lemons. Ann Thorac Surg. 2007; 83:1586-92.

11. Grunkemeier GL, Takkenberg JJ, Jamieson WR, Miller DC. Reporting "actual freedom" should not be banned. J Thorac Cardiovasc Surg. 2008;135:460-2.

12. Bourguignon T, Bouquiaux-Stablo AL, Candolfi P, Mirza A, Loardi C, May MA, et al. Very long-term outcomes of the Carpentier-Edwards Perimount valve in aortic position. Ann Thorac Surg. 2015;99:831-7.

13. McClure RS, Narayanasamy N, Wiegerinck E, Lipsitz S, Maloney A, Byrne JG, et al. Late outcomes for aortic valve replacement with the Carpentier-Edwards pericardial bioprosthesis: up to 17-year follow-up in 1,000 patients. Ann Thorac Surg. 2010;89:1410-6.

14. Jamieson WR, Germann E, Aupart MR, Neville PH, Marchand MA, Fradet GJ. 15-year comparison of supra-annular porcine and PERIMOUNT aortic bioprostheses. Asian Cardiovasc Thorac Ann. 2006;14:200-5.

15. Ruggieri VG, Flecher E, Anselmi A, Lelong B, Corbineau H, Verhoye JP, et al. Long-term results of the Carpentier-Edwards supraannular aortic valve prosthesis. Ann Thorac Surg. 2012;94:1191-7.
16. Leontyev S, Borger MA, Davierwala P, Walther T, Lehmann S, Kempfert J, et al Redo aortic valve surgery: early and late outcomes. Ann Thorac Surg. 2011;91: 1120-6.

17. Luciani N, Nasso G, Anselmi A, Glieca F, Gaudino M, Girola F, et al. Repeat valvular operations: bench optimization of conventional surgery. Ann Thorac Surg. 2006;81:1279-83.

18. Une D, Ruel M, David TE. Twenty-year durability of the aortic Hancock II bioprosthesis in young patients: is it durable enough? Eur J Cardiothorac Surg. 2014;46:825-30.

19. Bourguignon T, El Khoury R, Candolfi P, Loardi C, Mirza A, BoulangerLothion J, et al. Very long-term outcomes of the Carpentier-Edwards perimount aortic valve in patients aged 60 or younger. Ann Thorac Surg. 2015;100:853-9.

20. Forcillo J, El Hamamsy I, Stevens LM, Badrudin D, Pellerin M, Perrault LP, et al The perimount valve in the aortic position: twenty-year experience with patients under 60 years old. Ann Thorac Surg. 2014;97:1526-32.

21. Niclauss L, von Segesser LK, Ferrari E. Aortic biological valve prosthesis in patients younger than 65 years of age: transition to a flexible age limit? Interact Cardiovasc Thorac Surg. 2013;16:501-7.

22. Hammermeister KE, Sethi GK, Henderson WG, Oprian C, Kim T, Rahimtoola S. A comparison of outcomes in men 11 years after heart-valve replacement with a mechanical valve or bioprosthesis. Veterans Affairs Cooperative Study on Valvular Heart Disease. N Engl J Med. 1993;328: 1289-96.

23. Taylor KM. The Edinburgh heart valve study. Heart. 2003;89:697-8.

24. Stassano P, Di Tommaso L, Monaco M, Iorio F, Pepino P, Spampinato N, et al. Aortic valve replacement: a prospective randomized evaluation of mechanical versus biological valves in patients ages 55 to 70 years. J Am Coll Cardiol. 2009;54:1862-8.

25. Peterseim DS, Cen YY, Cheruvu S, Landolfo K, Bashore TM, Lowe JE, et al Long-term outcome after biologic versus mechanical aortic valve replacement in 841 patients. J Thorac Cardiovasc Surg. 1999;117:890-7.

26. Rahimtoola SH. Choice of prosthetic heart valve in adults an update. J Am Coll Cardiol. 2010;55:2413-26.

27. van Geldorp MW, Eric Jamieson WR, Kappetein AP, Ye J, Fradet GJ, Eijkemans MJ, et al. Patient outcome after aortic valve replacement with a mechanical or biological prosthesis: weighing lifetime anticoagulant-related event risk against reoperation risk. J Thorac Cardiovasc Surg. 2009;137:881-6. $886 \mathrm{e} 1-5$.

28. Dvir D, Webb JG, Bleiziffer S, Pasic M, Waksman R, Kodali S, et al. Transcatheter aortic valve implantation in failed bioprosthetic surgical valves. JAMA. 2014;312:162-70.

29. Kiefer P, Gruenwald F, Kempfert J, Aupperle H, Seeburger J, Mohr FW, et al. Crimping may affect the durability of transcatheter valves: an experimental analysis. Ann Thorac Surg. 2011;92:155-60.

30. Dvir D. First look at long-term durability of transcatheter heart valves: assessment of valve function up to 10 years after implantation. Presented at: EuroPCR; May 17, 2016; Paris, France.

Key Words: aortic valve replacement, bioprosthesis, durability 


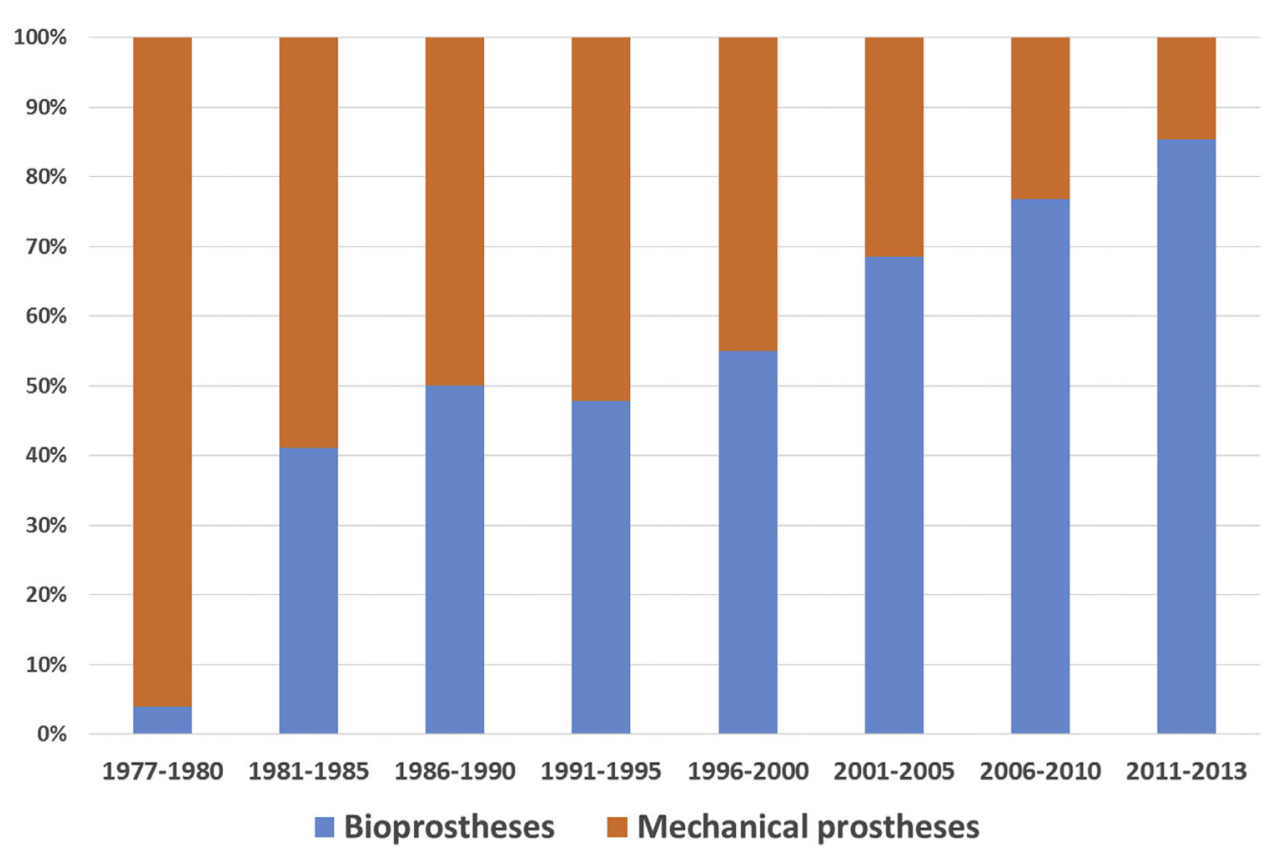

FIGURE E1. Evolution of the ratio of bioprostheses to mechanical valves used for AVR at our center from 1977 to 2013 (5-year strata).

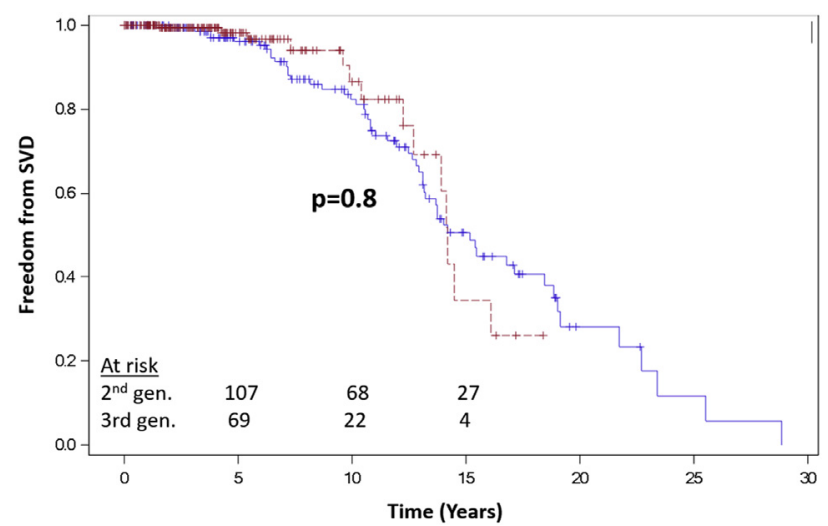

FIGURE E2. Kaplan-Meier curves for freedom from SVD stratified according to the second generation (blue line) and third generation (red line) of bioprostheses. SVD, Structural valve deterioration. 
TABLE E1. Perioperative characteristics and models of bioprostheses in the overall study population

\begin{tabular}{lc}
\hline \multicolumn{1}{c}{ Characteristic } & Value \\
\hline Nonelective priority, $\mathrm{n}(\%)$ & $58(14)$ \\
Cardiopulmonary bypass time, & $90.1 \pm 55$ \\
$\quad$ min, mean \pm SD & $70.1 \pm 43$ \\
Aortic cross-clamping time, min, & \\
$\quad$ mean \pm SD & \\
Type of bioprosthesis for aortic valve AVR, n & 117 \\
Carpentier-Edwards porcine & 123 \\
Carpentier-Edwards & \\
$\quad$ pericardial & 16 \\
St. Jude Epic & 31 \\
St. Jude Trifecta & 15 \\
Medtronic Intact & 8 \\
Medtronic Hancock & 91 \\
Medtronic Mosaic & 15 \\
Stentless (Medtronic & \\
$\quad$ Freestyle, Sorin Solo, & \\
$\quad$ Edwards Prima, Shelhigh) & \\
\hline
\end{tabular}

$S D$, Standard deviation; $A V R$, aortic valve replacement.

TABLE E2. Intergroup comparison of baseline variables

\begin{tabular}{|c|c|c|c|c|}
\hline Characteristic & Group $1(<40$ y) & Group $2(\geq 40$ and $<50$ y) & Group $3(\geq 50$ and $<60$ y) & $P$ value \\
\hline \multicolumn{5}{|l|}{ Etiology, \% } \\
\hline Infective endocarditis & 28.6 & 21.5 & 13.8 & $<.001$ \\
\hline Degenerative lesion & 5.2 & 15 & 28.9 & $<.001$ \\
\hline Rheumatic heart disease & 15.6 & 12.1 & 7.8 & .15 \\
\hline Marfan syndrome, $\%$ & 3.9 & 1.9 & 0.4 & .048 \\
\hline Male sex, $\%$ & 79.2 & 87.9 & 82.8 & .27 \\
\hline NYHA III/IV, \% & 32 & 43.4 & 52.8 & .005 \\
\hline Diabetes, $\%$ & 1.3 & 3.7 & 10.8 & .005 \\
\hline $\mathrm{LVEF}, \%$, mean $\pm \mathrm{SD}$ & $59.3 \pm 13.4$ & $58.9 \pm 12.3$ & $57.9 \pm 13.2$ & .74 \\
\hline Renal failure, $\%$ & 3.9 & 2.8 & 4.3 & .88 \\
\hline
\end{tabular}

NYHA, New York Heart Association; $L V E F$, left ventricular ejection fraction; $S D$, standard deviation. 
TABLE E3. Kaplan-Meier survival rates with confidence limits for event-free survival (stratified by age subgroup) concerning the endpoints reported in Figure 3

\begin{tabular}{|c|c|c|c|}
\hline $\begin{array}{c}\text { Characteristic and age } \\
\text { group }\end{array}$ & $\begin{array}{c}5-y \\
\text { follow-up }\end{array}$ & $\begin{array}{c}10-y \\
\text { follow-up }\end{array}$ & $\begin{array}{c}\begin{array}{c}15-y \\
\text { follow-up }\end{array}\end{array}$ \\
\hline \multicolumn{4}{|l|}{ Overall survival, $\%$} \\
\hline$<40 \mathrm{y}$ & $89.5 \pm 3.8$ & $86.4 \pm 4.8$ & $86.4 \pm 4.8$ \\
\hline$\geq 40$ and $<50 y$ & $85.3 \pm 3.8$ & $78.6 \pm 5.1$ & $68.8 \pm 8.1$ \\
\hline$\geq 50$ and $<60$ y & $80.3 \pm 3$ & $62.7 \pm 4.9$ & $48 \pm 6.6$ \\
\hline \multicolumn{4}{|l|}{ Freedom from SVD, \% } \\
\hline$<40 \mathrm{y}$ & $97.7 \pm 2.3$ & $85.5 \pm 6.1$ & $36.5 \pm 9.8$ \\
\hline$\geq 40$ and $<50 y$ & $95.7 \pm 2.5$ & $85 \pm 5.1$ & $48.9 \pm 8.3$ \\
\hline$\geq 50$ and $<60$ y & $97.6 \pm 1.4$ & $82.5 \pm 5.1$ & $57.8 \pm 8.8$ \\
\hline \multicolumn{4}{|c|}{ Freedom from reoperation for SVD, \% } \\
\hline$<40 \mathrm{y}$ & $97.7 \pm 2.3$ & $85.5 \pm 6.1$ & $43.4 \pm 10.2$ \\
\hline$\geq 40$ and $<50 y$ & $98.7 \pm 1.3$ & $86.1 \pm 5$ & $48.9 \pm 9.6$ \\
\hline$\geq 50$ and $<60 y$ & $97.6 \pm 1.4$ & $87.3 \pm 4.5$ & $70.8 \pm 8.5$ \\
\hline \multicolumn{4}{|l|}{ Freedom from SVD, $\%$} \\
\hline Porcine & $96.7 \pm 1.5$ & $85.8 \pm 3.4$ & $50.2 \pm 6$ \\
\hline Pericardial & $98.1 \pm 1.4$ & $78.4 \pm 7.6$ & $43.3 \pm 13$ \\
\hline
\end{tabular}

TABLE E4. Freedom from SVD stratified according to generation of bioprostheses

\begin{tabular}{lcclll}
\hline Generation & Total patients, $\mathbf{n}$ & SVD events, $\mathbf{n}$ & $\mathbf{5 - y}$ follow-up, $\%$ & 10-y follow-up, \% & 15-y follow-up, \% \\
\hline Second & 183 & 54 & $96.1(96.4)$ & $82.4(85.4)$ & $50.6(63.1)$ \\
Third & 218 & 14 & $98.2(98.4)$ & $86.6(88.8)$ & $34.6(46.9)$ \\
Total & 401 & 68 & 97 & 84.1 & 48.7 \\
\hline
\end{tabular}

Actuarial rates are reported; rates calculated with the competing-risks method are shown in parentheses. SVD, Structural valve deterioration. 
TABLE E5. Univariate and multivariate (Cox proportional hazards regression) predictors of mortality

\begin{tabular}{|c|c|c|c|c|}
\hline Variable & Univariate $P$ value & Multivariate $P$ value & $\mathbf{R R}$ & $95 \%$ CI \\
\hline Age & $<.001$ & $<.001$ & 1.061 & $1.03-1.09$ \\
\hline $\begin{array}{l}\text { New York Heart Association } \\
\text { class II }\end{array}$ & $<.001$ & .14 & & \\
\hline Left heart failure & $<.001$ & .003 & 1.909 & $1.23-2.94$ \\
\hline Right heart failure & .004 & .75 & & \\
\hline Obesity & .013 & .08 & & \\
\hline Peripheral arteriopathy & $<.001$ & $<.001$ & 3.181 & $1.69-5.98$ \\
\hline Hematologic disease & .01 & .22 & & \\
\hline Renal failure & .002 & .051 & & \\
\hline Respiratory insufficiency & .04 & .24 & & \\
\hline Hepatic failure & $<.001$ & $<.001$ & 2.964 & $1.67-5.25$ \\
\hline Cancer & .01 & .01 & 2.791 & $1.23-6.31$ \\
\hline Cardiopulmonary bypass time & $<.001$ & $<.001$ & 1.01 & $1-1.01$ \\
\hline Aortic cross-clamping time & .002 & .81 & & \\
\hline Nonelective & .019 & .07 & & \\
\hline
\end{tabular}

$R R$, Risk ratio; $C I$, confidence interval.

TABLE E6. Univariate and multivariate (Cox proportional hazards regression) predictors of SVD

\begin{tabular}{lccrc}
\hline \multicolumn{1}{c}{ Variable } & Univariate $\boldsymbol{P}$ value & Multivariate $\boldsymbol{P}$ value & RR & $\mathbf{9 5} \%$ CI \\
\hline Previous stroke & $<.001$ & $<.001$ & 10.88 & $1.11-37-97$ \\
Obesity & .05 & .03 & $1.93-3.56$ \\
Peripheral arteriopathy & .19 & .14 & 1.87 \\
$\begin{array}{l}\text { Combined stenosis and } \\
\quad \text { regurgitation }\end{array}$ & .02 & .02 & $1.07-3.25$ \\
\hline$R R$, Risk ratio; $\mathrm{CI}$, confidence interval. & & & \\
\hline
\end{tabular}

